\title{
Materials for Nuclear Energy
}

The ever-increasing demand for energy coupled with the growing concern about global warming has led to a resurgence of the commercial nuclear power industry. Pressurized water reactors and boiling water reactors have been significant sources of electricity for commercial use, providing approximately $20 \%$ of the U.S. grid, but nearly $70 \%$ of the electricity needs in France. Materials play key roles in the successful operation of light water reactor plants, from the structural and stainless steels and nickel-base alloys used in the PWR primary and secondary side systems, to the Zr-base alloys used in core applications, fuel systems, and waste. A series of overview articles dealing with selected materials aspects of nuclear power systems including glasses, stainless steels and welds, reactor pressure vessel steels, Ni-base alloys, and $\mathrm{Zr}$ alloys authored by recognized technical experts in the field will be published as part of this Energy Series in Metallurgical and Materials Transactions. The first two overviews deal with important scientific issues in materials for nuclear power applications: glasses for waste immobilization and the development and application of advanced atomistic models to understand how neutron irradiation affects microstructure in metals and alloys. Subsequent review articles will address specific materials (stainless steels, low alloy steels, Ni-base alloys, and $\mathrm{Zr}$ alloys) and will be published later.

M.G. Burke, Consultant

M.A. Burke

Westinghouse Materials Center of Excellence

Pittsburgh, PA 